ses and interpretation of findings. Patient led research typically presents numerical results and illustrates these with quotations to show what the data mean in terms of patients' lives, whereas clinical researchers tend to undertake further statistical analysis of the data, sometimes ignoring the original data.

The findings relate to the experience of persistent memory loss. Routine neuropsychological tests have been used in studies of electroconvulsive therapy to establish objective measures of memory loss and concluded that there was no evidence of persistent memory loss. It would seem that these are the studies on which the Royal College of Psychiatrists based its findings. The studies, however, typically measure the ability to form new memories after treatment (anterograde memory). Reports by patients of memory loss are of the erasing of autobiographical memories or retrograde amnesia. Thus the risks reported by patients do not appear in clinical assessments.

The levels of perceived benefit differed between patient led and clinician led studies because different methods were used and because in many cases these methods did not allow an adequate description of the complexity of subjective experience. Even where findings, such as persistent memory loss, did not differ between patient led and clinician led studies, the interpretations may have differed radically. It is therefore not surprising that disputes can arise and that organisations should emerge that provide support for those who feel their treatment has not been beneficial.

\section{Conclusion}

Although clinical trials concluded that electroconvulsive therapy is an effective treatment, ${ }^{5}$ measures of efficacy did not take into account all the factors that may lead patients to perceive it as beneficial or otherwise. Studies of treatment are needed that are able to investigate a range of outcomes valued by patients, including factors that impact on effectiveness and

\section{What is already known on this topic}

Around 11000 people receive electroconvulsive therapy in England annually

Controversy exists as to whether treatment is beneficial and whether patients are satisfied with it

Patients' views have never been systematically reviewed

\section{What this study adds}

At least one third of patients report significant memory loss after treatment

Routine neuropsychological tests to assess memory do not address the types of memory loss reported by patients

Reported patient satisfaction with electroconvulsive therapy depends on the methods used to elicit a response

satisfaction. Also important is loss of autobiographical memory, which is widely described but insufficiently systematically investigated.

Contributors: See bmj.com

Competing interests: This paper is based on a report funded by a grant from the Department of Health, England. The Department of Health has given permission for publication but does not necessarily endorse the views contained in the paper.

1 Department of Health. Electroconvulsive therapy: survey covering the period from January 1999 to March 1999, England. Stat Bull Crown Copyright, 1999.

2 Royal College of Psychiatrists. Fact sheet on ECT. London: RCP, 1995. Freeman C. Patients' attitudes towards ECT. Psychopharmacol Bull $1986 ; 22: 487-90$

Freeman CP, Cheshire KA. Attitude studies on electroconvulsive therapy. Convulsive Ther 1986;2:31-42.

5 The UK ECT Review Group. Efficacy and safety of electroconvulsive therapy in depressive disorders: a systematic review and meta-analysis. Lancet 2003;354:1369.

(Accepted 15 May 2003)

\title{
Outcome in people with open spina bifida at age 35: prospective community based cohort study
}

\author{
Gillian M Hunt, Pippa Oakeshott
}

\begin{abstract}
The introduction of the cerebrospinal fluid shunt led to a fourfold increase in survival of babies with open spina bifida in the United Kingdom. ${ }^{1}$ In 1963 a prospective independent review was set up to record the results and implications of the new treatment. ${ }^{23}$ Such data are crucial to the dilemmas associated with termination of affected pregnancies or treatment at birth. ${ }^{4}$ We investigated survival, disability, health, and lifestyles in a complete cohort of adults with spina bifida.
\end{abstract}

\section{Participants, methods, and results}

Between 1963 and 1971, 117 babies had their backs closed at Addenbrooke's Hospital, Cambridge, without any attempt at selection. Before closure of the back each baby had a full neurological examination. When necessary, hydrocephalus was controlled by the insertion of a ventriculoatrial shunt. In spring 2002 we reviewed the cohort by confidential postal questionnaire backed by a telephone call to the patient or carer. The Office for National Statistics provided information on deaths.

Ascertainment was $100 \%$. Sixty three (54\%) had died, mainly the most affected. Causes of death were cardiorespiratory (19) or renal (18) failure, hydrocephalus (10), central nervous system infection (10), convulsions (2), inhaled vomit (2), sudden infant death (1), and thrombocytopenic purpura (1). The mean age of the survivors was 35 years (range 32-38). The male:female ratio was $1: 1.3$, the same as at birth. Of the
Addenbrooke's

Hospital,

Cambridge

CB2 2QQ

Gillian M Hunt

retired research

clinician

continued over

BMJ 2003;326:1365-6 


\begin{tabular}{|c|c|c|c|c|c|}
\hline \multicolumn{5}{|c|}{$\begin{array}{l}\text { Neurological deficit in infancy in } 117 \text { consecutive cases of open spina bifida } \\
\text { and outcome in } 54 \text { people who survived to mean age } 35 \text { years }\end{array}$} & \multirow[b]{3}{*}{$\begin{array}{l}\text { P value } \\
\text { for trend }\end{array}$} \\
\hline & \multicolumn{4}{|c|}{ Sensory level in infancy } & \\
\hline & Below L3 & $\{3$ & 80 & Asymmetrical & \\
\hline Whole cohort & 38 & 32 & 42 & 5 & \\
\hline Those who died $(n=63)$ & 14 & 17 & 30 & 2 & $<0.01$ \\
\hline \multicolumn{6}{|c|}{ Disability and lifestyle in survivors (mean age 35 ): } \\
\hline Survivors & 24 & 15 & 12 & 3 & \\
\hline No CSF shunt $(\mathrm{n}=8)$ & 7 & 0 & 1 & 0 & $<0.05$ \\
\hline$I Q \geq 80(n=39) \dagger$ & 21 & 11 & 6 & 1 & 0.05 \\
\hline Community walker $(n=16) \ddagger$ & 16 & 0 & 0 & 0 & $<0.0001$ \\
\hline Continent $(n=11) \S$ & 8 & 2 & 0 & 1 & $<0.05$ \\
\hline Live independently $(n=22) \emptyset$ & 14 & 5 & 2 & 1 & $<0.05$ \\
\hline Drive cars $(n=20)$ & 14 & 4 & 2 & 0 & $<0.05$ \\
\hline Open employment ( $n=13$ ) & 9 & 2 & 2 & 0 & 0.18 \\
\hline $\begin{array}{l}{ }^{*} \chi^{2} \text { test. Asymmetrical sensc } \\
\dagger I Q \text { recorded at age } 5-15 \text { ye } \\
\neq \text { Able to walk } \geq 50 \text { metres w } \\
\S \text { Continent without catheter } \\
\text { ๆ Living in community witho }\end{array}$ & $\begin{array}{l}\text { ory level exc } \\
\text { ars. } \\
\text { ith aids if re } \\
\text { s or applian } \\
\text { ut help or s }\end{array}$ & from ana & & & \\
\hline
\end{tabular}

Department of Community Health St George's Hospital Medical School, London SW17 0RE

Pippa Oakeshott senior lecturer in general practice

Correspondence to: G M Hunt 65 Grantchester Street, Cambridge CB3 9HZ jill.poulton@ freeuk.com
54 survivors, 46 had a cerebrospinal fluid shunt, 39 had an IQ $\geq 80,16$ could walk 50 metres or more with or without aids, and only 11 were fully continent. Thirty had had pressure sores, and 30 were overweight. Mortality and disability were related to neurological deficit (figure).

In terms of lifestyle, 22 survivors lived independently in the community, though seven depended on a wheelchair. They managed their own lives including transport, continence care, pressure areas, and all medical needs. Twelve lived in sheltered accommodation, where help was available if required, and 20 needed daily help, mainly from a parent (now aged 52-77) or partner or from social services. All these 20 were severely disabled: two were blind after shunt dysfunction, and two were on respiratory support. However 20 of the survivors drove cars, although a further nine had given up driving. Thirteen worked in open employment, five of them in wheelchairs. Seven women and two men had had a total of 13 children, none of whom had visible spina bifida.

\section{Comment}

The outcome in this complete and unselected cohort ranged from apparent normality to severe disability. This reflected both the neurological deficit in terms of sensory level in infancy and the adverse events in the history of the shunt. ${ }^{5}$ Over one third of survivors continued to need daily care.

The community basis provides a fuller perspective than hospital based studies. Only a third of the survivors were still attending a hospital. Most were in the care of general practitioners, who had to manage problems associated with incontinence, pressure sores, sepsis, epilepsy, urinary and respiratory infections, hypertension, and obesity in addition to psychological distress or backache in the carer. Doctors need to know that headache, neck ache, drowsiness, deterioration in vision, or new eye signs may indicate shunt insufficiency, which requires prompt intervention to prevent serious long term consequences. ${ }^{5}$ The continuing needs of the large number of adult patients surviving from the era of non-selective treatment will have to be dealt with for many years. Given the limited benefits of treatment, the data we have gathered from this cohort provide those involved with counselling famillies affected by spina bifida with the clinical evidence to help them to make informed decisions.

We thank the patients and their carers.

Contributors: GMH had the idea, designed the study, and is guarantor. PO helped with analysis and writing the report.

Funding: Association for Spina Bifida and Hydrocephalus (ASBAH). The guarantor accepts full responsibility for the conduct of the study, had access to the data, and controlled the decision to publish.

Competing interests: None declared.

Ethical approval: Cambridge LREC (reference 02/105).

\footnotetext{
Laurence K. Effect of early surgery for spina bifida on survival and quality of life. Lancet 1974;i:301-4

Hunt GM, Lewin L, Gleave J, Gairdner D. Predictive factors in open myelomeningocele with special reference to sensory level. BMJ 1973;iv:197-201.

3 Hunt GM, Poulton A. Open spina bifida: a complete cohort reviewed 25 years after closure. Dev Med Child Neurol 1995;37:19-29.

Smith GK, Smith ED. Selection for treatment in spina bifida cystica. BMJ 1973;iv:189-97.

5 Hunt GM, Oakeshott P, Kerry S. Link between the CSF shunt and achievement in adults with spina bifida. J Neurol Neurosurg Psychiatry $1999 ; 67: 591-5$
}

(Accepted 15 February 2003)

\section{One hundred years ago}

\section{A vaccination compliment}

The wife of Major-General Chambers, of 11, Trinity Gardens, Folkestone, recently paid the public vaccinator of Folkstone one of those delicate compliments of which only well-to-do women are capable. She apparently regards vaccination as too important an operation to be entrusted to an ordinary medical man, so, when she felt that she and her two daughters were in need of it, she selected one who may be regarded as a vaccination specialist. Many quite ordinary people, with whom we would not for a moment class the wife of a major-general, think and do the same, and the supreme delicacy of Mrs. Chambers's conduct lies in the fact that, instead of being content to pay the public vaccinator a compliment in the surgery where he sees his official patients, she made it a direct and personal one by seeking him out with her two daughters in his private consulting room. Unfortunately, however, after this she rather spoiled the thing by refusing to pay his fees, and the intervention of another of H. M. officers, in the shape of the county court judge, had to be invoked before she rounded off her compliment by the noble fee of half a crown a head. Half a guinea was the fee that had been suggested, and it really seems more appropriate. Medical men are too modest a race really to enjoy the compliments so frequently paid by the public to their philanthropic instincts, and have too much artistic taste not to see that "lily" compliments like this should, if painted at all, be gilt with the finest gold.
(BMJ 1903;i:1227) 